\title{
Inhibitory effect of Ti-Ag alloy on artificial biofilm formation
}

\author{
Kazuko NAKAJO ${ }^{1}$, Masatoshi TAKAHASHI², Masafumi KIKUCHI ${ }^{3}$, Yukyo TAKADA², Osamu OKUNO², \\ Keiichi SASAKI ${ }^{4}$ and Nobuhiro TAKAHASHI ${ }^{1}$

\begin{abstract}
${ }^{1}$ Division of Oral Ecology and Biochemistry, Tohoku University Graduate School of Dentistry, 4-1 Seiryo-machi, Aoba-ku, Sendai 980-8575, Japan ${ }^{2}$ Division of Dental Biomaterials, Tohoku University Graduate School of Dentistry, 4-1 Seiryo-machi, Aoba-ku, Sendai 980-8575, Japan 890-8544, Japan

${ }^{4}$ Division of Advanced Prosthetic Dentistry, Tohoku University Graduate School of Dentistry, 4-1 Seiryo-machi, Aoba-ku, Sendai 980-8575, Japan Corresponding author, Nobuhiro TAKAHASHI; E-mail: nobu-t@dent.tohoku.ac.jp
\end{abstract} \\ ${ }^{3}$ Department of Biomaterials Science, Kagoshima University Graduate School of Medical and Dental Sciences, 8-35-1 Sakuragaoka, Kagoshima
}

\begin{abstract}
Titanium-silver (Ti-Ag) alloy has been improved for machinability and mechanical properties, but its anti-biofilm properties have not been elucidated yet. Thus, this study aimed to evaluate the effects of Ti-Ag alloy on biofilm formation and bacterial viability in comparison with pure $\mathrm{Ti}$, pure $\mathrm{Ag}$ and silver-palladium (Ag-Pd) alloy. Biofilm formation on the metal plates was evaluated by growing Streptococcus mutans and Streptococcus sobrinus in the presence of metal plates. Bactericidal activity was evaluated using a film contact method. There were no significant differences in biofilm formation between pure Ti, pure Ag and Ag-Pd alloy, while biofilm amounts on $\mathrm{Ti}-20 \% \mathrm{Ag}$ and $\mathrm{Ti}-25 \% \mathrm{Ag}$ alloys were significantly lower $(p<0.05)$. In addition, $\mathrm{Ti}-\mathrm{Ag}$ alloys and pure Ti were not bactericidal, although pure Ag and Ag-Pd alloy killed bacteria. These results suggest that Ti-20\% Ag and Ti-25\% Ag alloys are suitable for dental material that suppresses biofilm formation without disturbing healthy oral microflora.
\end{abstract}

Keywords: Anti-adhesion, Antibacterial activity, Anti-biofilm, Mutans streptococci, Ti-Ag alloy

\section{INTRODUCTION}

It has been estimated that a tremendous number and over 500 species of microorganisms inhabit the human oral cavity ${ }^{1,2)}$. These microorganisms usually play a role in protection against pathogenic microbial invasion and the maintenance of oral health ${ }^{3,4}$. However, once microorganisms begin to form biofilm on the oral surfaces, e.g., teeth, oral mucosa, as well as on the surface of dental materials, they are capable of initiating and promoting oral diseases such as dental caries and periodontal diseases. Furthermore, biofilm formed on material surfaces may cause biological deterioration of the materials $\mathrm{s}^{5,6}$. Therefore, dental materials that decrease biofilm formation on their surfaces are desired for oral health promotion, as well as long-term use of dental materials.

Titanium (Ti) has been widely utilized as a biomaterial ${ }^{7,8}$, including dental materials, as it has advanced corrosion resistance and biocompatibility. Ti is used mainly for dental implants and dental prostheses. Dental implants penetrate not only bone but also gingiva, so they are partially exposed to oral microflora. Dental prostheses are also exposed to the oral cavity. Accordingly, it is ideal that materials for dental implants and prostheses possess antibacterial activity. However, it has been reported that Ti itself has no inhibitory effect on bacterial growth compared with other metals ${ }^{9,10)}$, and the amount of biofilm on $\mathrm{Ti}$ is similar to that formed on other dental materials ${ }^{11}$. Biofilm formation surrounding implants may cause peri-implantitis ${ }^{12,13)}$, while biofilm on dental prostheses may induce inflammatory lesions, such as denture

Received Nov 26, 2013: Accepted Feb 19, 2014

doi:10.4012/dmj.2013-334 JOI JST.JSTAGE/dmj/2013-334 stomatitis ${ }^{14,15)}$. Thus, it is important to prevent biofilm formation on the surfaces of dental implants and prostheses to ensure long-term clinical success.

Some mechanical properties of $\mathrm{Ti}$ are insufficient, such as strength and machinability, for dental materials. However, recent improvement by the development of a titanium-silver (Ti-Ag) alloy has solved these problems ${ }^{16-18)}$. Meanwhile, it is well known that Ag exhibits broad-spectrum antimicrobial activity ${ }^{19}$. So far, previous studies have demonstrated that $\mathrm{Ti}-2 \% \mathrm{Ag}$ alloy has little effect on the viability of Lactobacillus acidophilus and Streptococcus mutans, similar to $\mathrm{Ti}^{20,21)}$, although there are no detailed reports on the antimicrobial activity of Ti-Ag alloy.

Thus, this study aimed to evaluate the inhibitory effects on both biofilm formation and antibacterial activity of Ti-Ag alloys, which have already improved machinability and mechanical properties ${ }^{16-18)}$, and to compare with those of pure $\mathrm{Ti}$, pure $\mathrm{Ag}$ and dental silver-palladium (Ag-Pd) alloy.

\section{MATERIALS AND METHODS}

\section{Preparation of alloy specimen}

Procedures for the preparation of Ti-Ag alloys have been described in detail previously ${ }^{22}$. Experimental $\mathrm{Ti}$ alloys with 10, 20, 25 and $30 \% \mathrm{Ag}$ were examined in the present study. Amounts of Ti sponge (>99.8\%, grade S-90, Osaka Titanium Technologies Co., Ltd., Amagasaki, Japan) and pure silver (>99.99\%, Ishifuku Metal Industry Co., Ltd., Tokyo, Japan) were melted into $15 \mathrm{~g}$ button ingots of each alloy in an argon arc melting furnace (TAM-4S, Tachibana Riko, Sendai, Japan). Pure titanium ingots were made in the same manner. 
Each ingot was cast into a plate pattern $(15 \mathrm{~mm}$ long $\times 10 \mathrm{~mm}$ wide $\times 1.9 \mathrm{~mm}$ thick) using a magnesia investment (Selevest CB, Selec, Osaka, Japan) in a two-compartment argon gas pressure casting unit (Castmatic-S, Iwatani, Osaka, Japan) at $200^{\circ} \mathrm{C}$ and was then bench-cooled. All the surfaces of the cast plates were abraded to a depth of 180-800 $\mu \mathrm{m}$ using silicon carbide abrasive paper to remove the hardened surface layer on the casting. Pure Ag and a dental Ag-Pd alloy (46\%Ag-20\% Pd-20\%Cu-12\%Au alloy) (Castwell M.C., GC, Tokyo, Japan) plate specimens were also prepared as controls. These specimens were ultrasonically cleaned in 99\% ethanol and distilled water and then sterilized by autoclave.

\section{Biofilm formation on alloy specimen}

Two trains of mutans streptococci, Streptococcus mutans ATCC 31989 and Streptococcus sobrinus 6715 were used in the present study. These bacteria were inoculated in brain-heart infusion (BHI) broth (Difco Laboratories, Detroit, MI, USA) and pre-cultured at $37^{\circ} \mathrm{C}$ overnight. A piece of nylon string was wound around each specimen, which was placed in a horizontal position separated from the bottom of the culture vessel (Fig. 1). Each culture vessel was filled with $5.0 \mathrm{~mL}$ complex medium containing 1.7\% tryptone (Difco Laboratories), $0.3 \%$ yeast extract (Oxoid, Basingstoke, Hampshire, UK), $0.5 \% \mathrm{NaCl}, 50 \mathrm{mM}$ potassium phosphate and $0.5 \%$ sucrose (TYS culture media), which was autoclaved before $0.5 \%$ sucrose and $50 \mathrm{mM}$ potassium phosphate buffer were added using a sterile membrane filter (pore size $0.2 \mu \mathrm{m}$; Pall corporation, Pall Newquay, Cornwall, UK). The cell culture in BHI broth was transferred (5\% inoculum size) to the vessel and incubated at $37^{\circ} \mathrm{C}$ in the presence of one of the specimens.

Biofilm formation was conducted in an anaerobic chamber $\left(80 \% \mathrm{~N}_{2}, 10 \% \mathrm{H}_{2}\right.$ and $10 \% \mathrm{CO}_{2}$, NHC-type; Hirasawa Works, Tokyo, Japan). After 12 h, bacterial accumulation on the specimens was observed visually. The bacterial accumulation was removed by gentle vibration in distilled water, and then bacteria firmly adhered to the specimens were collected by scraping with a sterile plastic spatula. These samples were suspended in distilled water and the amounts of bacteria were estimated by measuring optical density (OD) at $660 \mathrm{~nm}$ with a spectrophotometer (UV-160, Shimadzu Corporation, Kyoto, Japan). The amount of bacteria was defined as the amount of biofilm formed.

\section{Antibacterial activity of alloy specimen}

S. mutans ATCC 31989 and S. sobrinus 6715 were inoculated in BHI broth and pre-cultured at $37^{\circ} \mathrm{C}$ overnight. The cell culture was transferred (5\% inoculum size) to the complex medium, as described above, except that sucrose was replaced by glucose. After incubation in the anaerobic chamber at $37^{\circ} \mathrm{C}$ until the late-log growth phase $(\mathrm{OD}=0.9-1.0$ at $660 \mathrm{~nm})$, the cell culture was taken from the chamber, harvested and washed three times by centrifuging $(21,000 \times \mathrm{g}$ for $7 \mathrm{~min}$ at $4^{\circ} \mathrm{C}$ ) in buffer solution containing $2 \mathrm{mM}$ potassium

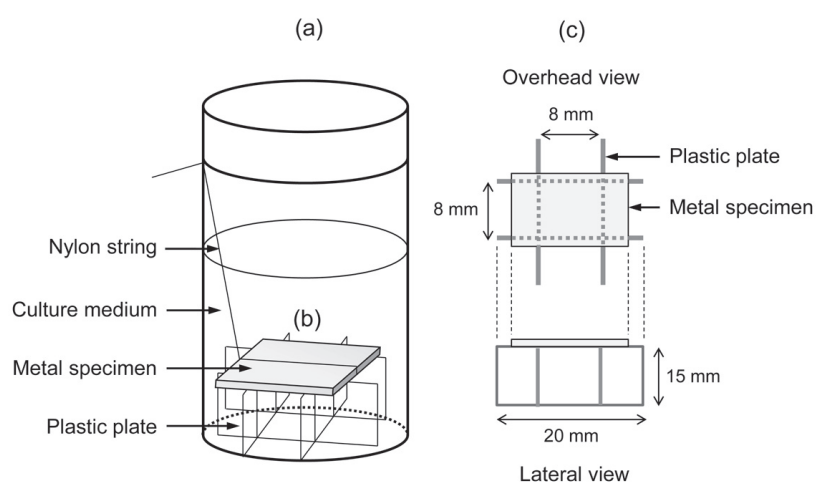

Fig. 1. Schematic drawing of the experimental apparatus. (a) Culture vessel for biofilm formation on metal specimen. (b) Device for setting the specimen in a horizontal position with a separation from the bottom of culture vessel. (c) Structural drawing of (b).

phosphate buffer ( $\mathrm{pH}$ 7.0), $150 \mathrm{mM} \mathrm{KCl}$ and $5 \mathrm{mM}$ $\mathrm{MgCl}_{2}(\mathrm{PPB})$.

The cells were suspended in PPB at OD of 0.15 at $660 \mathrm{~nm}$, and $5 \mu \mathrm{L}$ cell suspension was pipette onto the surface of each specimen. To spread the cell suspension on the surface, it was covered with plastic film $(5 \times 5$ $\mathrm{mm})$. Each specimen was then incubated at $37^{\circ} \mathrm{C}$ and $90 \%$ relative humidity under aerobic conditions. After $2 \mathrm{~h}$, bacterial cells on the specimen were washed off and homogenized with $2 \mathrm{~mL}$ PPB in a sterile plastic bag, and $0.1 \mathrm{~mL}$ bacterial suspension was taken from the bag. The sample was serially diluted with PPB and spread on TYG agar plates ( $\mathrm{pH}$ 7.0). The plates were incubated at $37^{\circ} \mathrm{C}$ for 2 days in the anaerobic chamber, and colonyforming units were counted. This analysis was designed based on the JIS Z 2801 test $^{23)}$.

\section{Surface roughness}

The surface roughness of the specimens was measured using a surface profilometer (Surfcom 480A, Tokyo Seimitsu, Tokyo, Japan) with an evaluation length of $4.0 \mathrm{~mm}$, a stylus speed of $0.6 \mathrm{~mm} \mathrm{~s}^{-1}$, and a cutoff value of $0.8 \mathrm{~mm}$. Surface roughness was characterized by the height parameter, $R a$, which is the arithmetical mean of the absolute values of the profile departures within the length evaluated. Three randomly chosen positions on each specimen surface were measured.

\section{Statistical analysis}

Differences in the amount of biofilm were analyzed by one-way ANOVA and the Tukey HSD test. Significant differences were considered at $p<0.01$. The $R a$ data were statistically analyzed by one-way ANOVA and the Tukey HSD test at a significance level of $\alpha=0.05$.

\section{RESULTS}

Biofilm formation on alloy specimen

Similar bacterial accumulation was observed on all the 
specimens after overnight incubation with bacterial cells. Although bacterial accumulation was removed by vibration, biofilm remained on the surface of the specimens. The amount of biofilm firmly formed on TiAg alloys seemed to be lower than on pure Ti (Fig. 2).

The amount of biofilm scraped and measured with a spectrophotometer showed no significant difference among pure $\mathrm{Ti}$, pure $\mathrm{Ag}$ and the $\mathrm{Ag}-\mathrm{Pd}$ alloy with both streptococcal strains. However, the amount of biofilm formed on Ti-Ag alloys with 20 and $25 \% \mathrm{Ag}$ by $\mathrm{S}$. mutans, and on Ti-Ag alloy with $25 \% \mathrm{Ag}$ by $\mathrm{S}$. sobrinus was significantly lower $(p<0.01)$ than on pure Ti (Fig. 3).

\section{Antibacterial activity of alloy specimen}

Pure Ag and the Ag-Pd alloy exhibited efficient bactericidal activity against both streptococcal strains, (a)

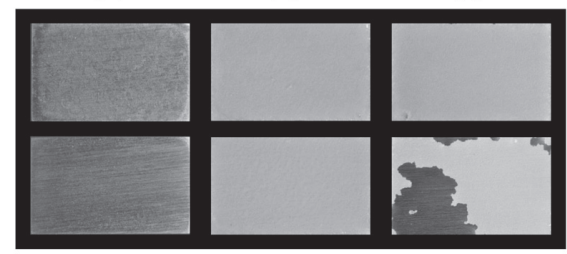

Fig. 2. Digital photograph showing typical example of the changes in the surfaces of metal specimen.

(a) Images of metal specimen before culture of $S$. mutans. (b) Images of metal specimen after culture of $S$. mutans. (c) Images of metal specimen after vibration treatment.

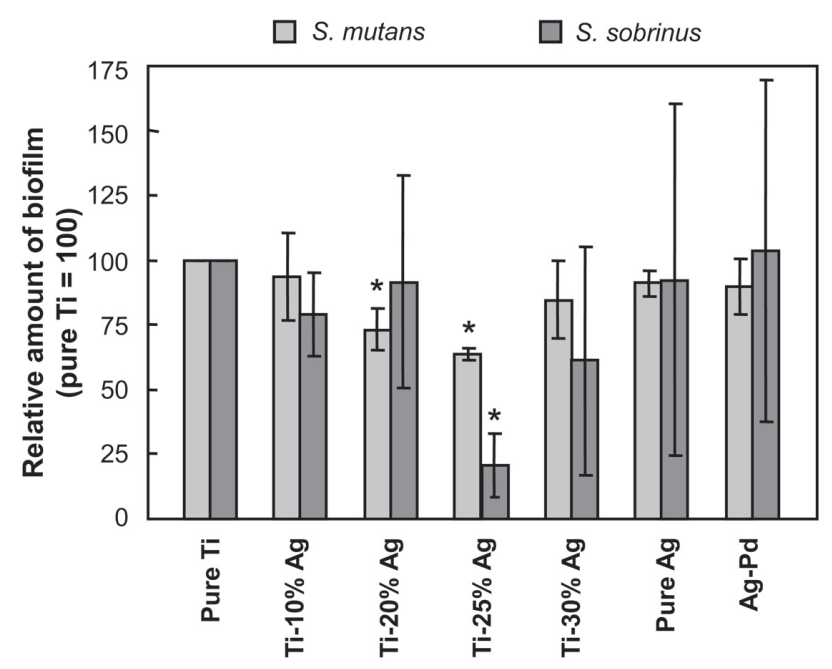

Fig. 3. Relative amount of biofilm scraped from the surfaces of each specimen.

The amount of biofilm from pure Ti was regarded as 100 . The data are the means of 3 independent experiments. Vertical bars indicate standard deviation. *, significantly difference from pure $\mathrm{Ti}$ $(p<0.01)$. with both bacteria killed completely by direct contact with the metals for $2 \mathrm{~h}$ (Fig. 4). In contrast, the Ti$\mathrm{Ag}$ alloys as well as pure $\mathrm{Ti}$ showed no bactericidal activity.

\section{Surface roughness}

When compared with pure titanium, Ti-25\% Ag alloy, pure silver and Ag-Pd alloy had significantly lower $(p<0.01)$ surface roughness $(R a)$ (Fig. 5). The $R a$ value for $\mathrm{Ti}-25 \% \mathrm{Ag}$ alloy was significantly lower $(p<0.05)$ than that for pure silver but significantly higher $(p<0.05)$ than that for Ag-Pd alloy.

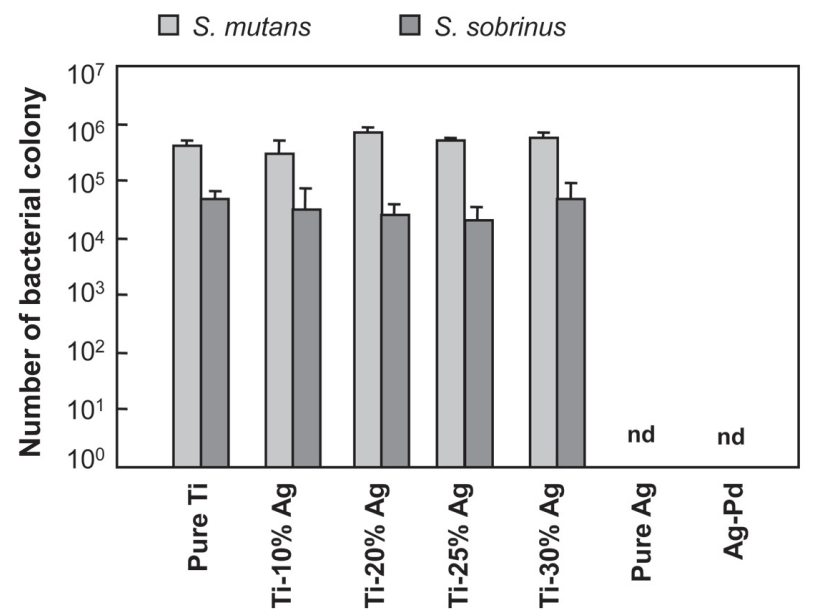

Fig. 4. Number of bacterial colony recovered after direct contact to metal specimen for $2 \mathrm{~h}$ at $37^{\circ} \mathrm{C}$ and $90 \%$ relative humidity.

The data are the means of 3 independent experiments. Vertical bars indicate standard deviation. nd, not detected.

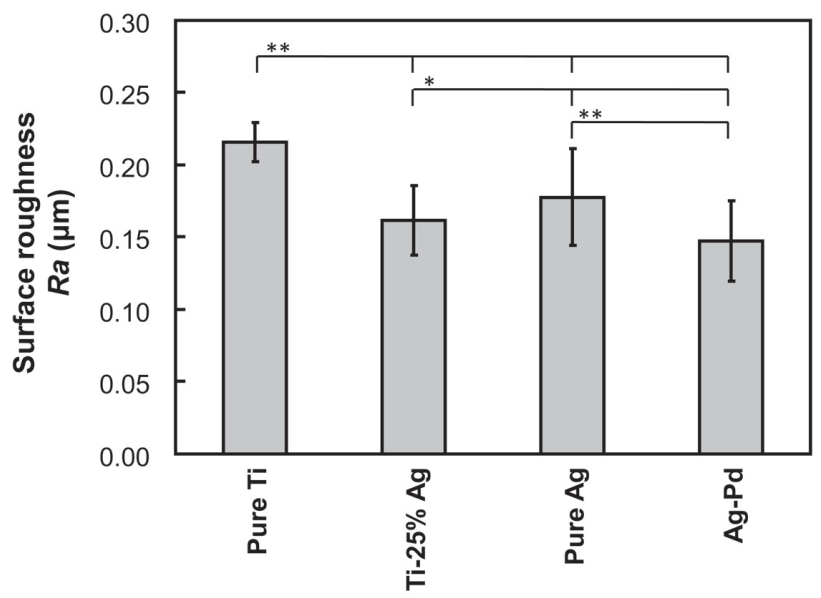

Fig. 5. Surface roughness $(R a)$ values of metal specimens. The data are the means of 48 independent experiments.

Vertical bars indicate standard deviation. $*: p<0.05,{ }^{* *}: p<0.01$. 


\section{DISCUSSION}

The present study showed that Ti-Ag alloys inhibited biofilm formation on the surface (Figs. 2 and 3), but were not bactericidal (Fig. 4). These findings suggest that Ti-Ag alloys have anti-biofilm properties that inhibit bacterial adhesion and colonization of the surface, but do not affect bacterial viability. Although it is unknown why the inhibitory effect on biofilm formation of S. sobrinus highly varied (Fig. 3), Ti-Ag alloys, especially $\mathrm{Ti}-25 \% \mathrm{Ag}$ alloy clearly inhibited the biofilm formation.

In the oral cavity, there are a tremendous number and species of microorganisms, and these bacteria comprise indigenous oral microbiota, which are crucial to protect the oral environment from the invasion of external pathogenic bacteria ${ }^{3,4)}$. Antibacterial agents, such as antibiotics and antibacterial materials, are important to control infectious sites, such as dental pulp-infected caries lesions and deep periodontal pockets; however, in the healthy oral environment, the antibacterial agents may kill or weaken the beneficial indigenous bacteria, and subsequently cause microbial substitution if used long term. For dental materials, particularly restorative and prosthetic materials, which are always exposed to the oral cavity and interact with oral indigenous bacteria, active antibacterial properties are probably not required. From these points of view, Ti-Ag alloy is considered to be a feasible material for dental use. In addition, sufficient anti-biofilm properties were shown by the Ti-Ag alloys with $20 \%$ and $25 \% \mathrm{Ag}$ (Fig. 3), which were previously reported to have the good corrosion resistance, mechanical properties and machinability among Ti-Ag alloys containing various concentrations of silver ${ }^{16-18,22)}$. The present study, together with our previous studies, suggests that Ti-Ag alloys with $20 \%$ and $25 \% \mathrm{Ag}$ are promising candidates for dental materials.

The mechanisms by which Ti-Ag alloys inhibit bacterial adhesion are still unclear at present. Surface roughness is known to be one of the crucial determinants of bacterial adhesion, and it is reported that the surface roughness less than $0.2(R a<0.2)$ decreases bacterial adhesion to the surface of materials ${ }^{24}$. Our observation (Fig. 5) indicates that Ti-Ag alloy had significantly lower surface roughness $(R a)$ than pure Ti, suggesting that the lower surface roughness may partly contribute to low bacterial adherence of $\mathrm{Ti}-\mathrm{Ag}$ alloy. However, pure $\mathrm{Ag}$ and $\mathrm{Ag}-\mathrm{Pd}$, which had a significant lower surface roughness than pure $\mathrm{Ti}$, did not show any anti-biofilm activity, indicating that the low surface roughness alone does not explain the low bacterial adherence of Ti-Ag alloys.

It is well known that silver and most silver alloys are bactericidal ${ }^{19)}$, as shown in the present study (pure $\mathrm{Ag}$ and $\mathrm{Ag}-\mathrm{Pd}$ alloy in Fig. 4), since silver ions are released from the materials ${ }^{25}$ and the ions inhibit bacterial physiological properties ${ }^{26}$. In the case of Ti-Ag alloys, however, it is reported that silver ions are not released from the alloys under physiological conditions $^{27,28)}$. This property could be the reason why Ti-Ag alloys are not anti-bacterial or bactericidal. Titanium alloys are known to easily form a titanium oxide layer on the surface ${ }^{29)}$; thus silver atoms in the alloys might be embedded and/or surrounded by the oxide layer, and seldom released from the surface. However, as discussed above, the property of the titanium surface can be modified by the addition of silver in terms of bacterial adhesion and colonization.

The zeta potential is known to affect bacterial adhesion $^{30)}$. The observation that the open circuit potential of Ti-Ag alloys differed from that of titanium $^{27,28)}$ suggest that the zeta potential may also be different. Silver atoms embedded and/or surrounded by a titanium oxide layer might influence the zeta potential, resulting in decrease of the affinity between bacteria and the metal surface, which could be most effective with a silver concentration of $25 \%$ in the alloy. This effect of silver atoms would be advantageous for long-term used dental materials such as restorative and denture materials, since silver atoms would maintain their anti-biofilm activity as long as they remain. In the previous study ${ }^{31)}$, another type of $\mathrm{Ti}-\mathrm{Ag}$ alloy with silver particles on the surface was reported to have antibacterial activity; however, this antibacterial activity is due to silver ions released from silver particles, as described above, and thus will weaken along with decrease of silver particles.

Pure Ag and Ag-Pd alloys had bactericidal activity that was capable of killing mutans streptococci completely after 2 -h direct contact with these metal surfaces (Fig. 4); however, these metals did not inhibit biofilm formation (Fig. 3). These controversial observations may be explained as follows. Once bacteria adhere to the metal surface, the adhered bacteria can inhibit the release and diffusion of silver ions from the metal surface and mask the bactericidal activity of the metals, irrespective of bacterial viability. Bacteria can subsequently adhere to and grow on the bacteria-coated metal surface without metal-derived bactericidal activity.

In the present study, only two strains of mutans streptococci were used for artificial biofilm formation under a limited experimental condition, which could be different from that in vivo in the oral cavity. Although this model study is beneficial to compare and standardize biofilm formation and anti-biofilm activity among test materials, further study using various oral bacteria and/or an in vivo experiment, e.g. biofilm formation on test materials in the oral cavity, is desired in the future.

\section{CONCLUSION}

The present study showed that Ti-Ag alloys, particularly Ti-25\% Ag alloy, inhibited artificial biofilm formation on the surface and that this anti-biofilm property was not bactericidal. Together with previous findings of the good corrosion resistance, mechanical properties and machinability of $\mathrm{Ti}-20 \% \mathrm{Ag}$ and $\mathrm{Ti}-25 \% \mathrm{Ag}$ alloys, these 
alloys could be suitable for dental materials such as restorative and prosthetic materials.

\section{ACKNOWLEDGMENTS}

This study was supported in part by Grants-in-Aid for Scientific Research B (19390539 and 22390399), for Scientific Research C (24592948) and for Young Scientists B (20791632 and 23792498), JSPS, Japan, and in part by Research and Education Funding for the Inter-University Research Project (2007-2011), MEXT, Japan.

\section{REFERENCES}

1) Moore WE, Moore LV. The bacteria of periodontal diseases. Periodontol 2000 1994; 5: 66-77.

2) Aas JA, Paster BJ, Stokes LN, Olsen I, Dewhirst FE. Defining the normal bacterial flora of the oral cavity. J Clin Microbiol 2005; 43: 5721-5732.

3) Marsh PD. Microbial ecology of dental plaque and its significance in health and disease. Adv Dent Res 1994; 8: 263271.

4) Marsh PD. Role of the oral microflora in health. Microb Ecol Health Dis 2000; 12: 130-137.

5) Beech IB, Sunner J. Biocorrosion: towards understanding interactions between biofilms and metals. Curr Opin Biotechnol 2004; 15: 181-186.

6) Beech IB, Sunner JA, Arciola CR, Cristiani P. Microbiallyinfluenced corrosion: damage to prostheses, delight for bacteria. Int J Artif Organs 2006; 29: 443-452.

7) Howlett CR, Evans MD, Walsh WR, Johnson G, Steele JG. Mechanism of initial attachment of cells derived from human bone to commonly used prosthetic materials during cell culture. Biomaterials 1994; 15: 213-222.

8) Gronowicz G, MaCathy MB. Response of human osteoblasts to implant materials: integrin-mediated adhesion. J Orthop Res 1996; 14: 878-887.

9) Joshi RI, Eley A. The in-vitro effect of a titanium implant on oral microflora: comparison with other metallic compounds. J Med Microbiol 1988; 27: 105-107.

10) Elagli K, Neut C, Romond C, Hildebrand HF. In vitro effects of titanium powder on oral bacteria. Biomaterials 1992; 13: 25-27.

11) Leonhardt A, Olsson J and Dahlen G. Bacterial colonization on titanium, hydroxyapatite, and amalgam surfaces in vivo. $\mathrm{J}$ Dent Res 1995; 74: 1607-1612.

12) Shibli JA, Melo L, Ferrari DS, Figueiredo LC, Faveri M, Feres M. Composition of supra- and subgingival biofilm of subjects with health and diseases implants. Clin Oral Implants Res 2008; 19: 975-982.

13) Koyanagi T, Sakamoto M, Takeuchi Y, Ohkuma M, Izumi Y. Analysis of microbiota associated with peri-implantitis using 16S rRNA gene clone library. J Oral Microbiol 2010; 2: 5104-
5110.

14) Ramage G, Tomsett K, Wickes BL, López-Ribot JL, Redding SW. Denture stomatitis: a role for Candida biofilms. Oral Surg Oral Med Oral Pathol Oral Radiol Endod 2004; 98: 5359.

15) Mantzourani M, Gilbert SC, Fenlon M, Beighton D. Nonoral bifidobacteria and the aciduric microbiota of the denture plaque biofilm. Mol Oral Microbiol 2010; 25:190-199.

16) Takahashi M, Kikuchi M, Takada Y, Okuno O. Mechanical properties and microstructures of dental cast $\mathrm{Ti}-\mathrm{Ag}$ and $\mathrm{Ti}$ $\mathrm{Cu}$ alloys. Dent Mater J 2002; 21: 270-280.

17) Kikuchi M, Takahashi M, Okabe T, Okuno O. Grindability of dental cast Ti-Ag and Ti-Cu alloys. Dent Mater J 2003; 22: 191-205.

18) Kikuchi M, Takahashi M, Okuno O. Machinability of experimental Ti-Ag alloys. Dent Mater J 2008; 27: 216-220.

19) Grier N. In: Block SS, editor. Disinfection, Sterilization and Preservation. 3rd ed. Philadelphia: Lea and Febiger; 1983. p. 375-389.

20) Choi JY, Kim KH, Choy KC, Oh KT, Kim KN. Photocatalytic antibacterial effect of $\mathrm{TiO}(2)$ film formed on $\mathrm{Ti}$ and $\mathrm{TiAg}$ exposed to Lactobacillus acidophilus. J Biomed Mater Res B Appl Biomater 2007; 80: 353-359.

21) Choi JY, Chung CJ, Oh KT, Choi YJ, Kim KH. Photocatalytic antibacterial effect of $\mathrm{TiO}(2)$ film of TiAg on Streptococcus mutans. Angle Orthod 2009; 79: 528-532.

22) Takahashi M, Kikuchi M, Takada Y, Okabe T, Okuno O. Electrochemical behavior of cast Ti-Ag alloys. Dent Mater J 2006; 25: 516-523.

23) JIS Z 2801. In: Antimicrobial products-Test for antimicrobial activity and efficacy. Japanese Standard Association; 2000. p. 1-19.

24) Bollen CM, Lambrechts P, Quirynen M. Comparison of surface roughness of oral hard materials to the threshold surfaceroughness for bacterial plaque retention: a review of the literature. Dent Mater 1997; 13: 258-269.

25) Takada Y. Corrosion resistance of dental alloys evaluated from released ions. Corrosion Engineering 2000; 49: 669-685.

26) Williams RL, Doherty PJ, Vince DG, Grashoff GJ, Williams DF. The biocompatibility of silver. Crit Rev Biocompat 1989; 5: 221-244.

27) Takahashi M, Kikuchi M, Takada Y, Okuno O. Corrosion resistance of dental Ti-Ag alloys in $\mathrm{NaCl}$ solution. Mater Trans 2010; 51: 762-766.

28) Takahashi M, Kikuchi M, Takada Y. Corrosion behavior of Ti-Ag alloys used in dentistry in lactic acid solution. Met Mater Int 2011; 17: 175-179.

29) Oshida Y. In: Oshida Y, editor. Bioscience and bioengineering of titanium materials. Amsterdam: Elsevier; 2007. p. 81-86.

30) Satou J, Fukunaga A, Satou N, Shintani H, Okuda K. Streptococcal adherence on various restorative materials. J Dent Res 1988; 67: 588-591.

31) Kang MK, Moon SK, Kwon JS, Kim KM, Kim KN. Antibacterial effect of sand blasted, large-grit, acid-etched treated Ti-Ag alloys. Mater Res Bull 2012; 47: 2952-2955. 